\title{
Non-Operative Management of Splenic Injuries (NOMSI) in a Limited Resources Setup
}

\author{
Sami E E Salah ${ }^{1 *}$, Sami GEE Mohammed ${ }^{2}$, Marwa 0 Zeinelabdeen ${ }^{3}$, Saeed M Omar ${ }^{4}$ and Majdi A 0 Bakhiet ${ }^{5}$ \\ ${ }^{1} M D$, FACS Associate Prof. of Surgery, University of Gadarif, Sudan
}

${ }^{2} M D$, FACS, FRCS Assistant Prof. of Surgery, University of Gadarif, Sudan

${ }^{3}$ Surgery Resident at Sudan Medical Specialization Board, University of Gadarif, Sudan

${ }^{4} M D$, Associate Prof of Medicine, University of Gadarif, Sudan

${ }^{5} \mathrm{MD}$, Assistant Prof of Surgery, University of Gadarif, Sudan

Submission: February 02, 2020; Published: October 02, 2020

*Corresponding author: Sami Eldirdiri, MD, FACS Associate Prof. of Surgery, University of Gadarif, Sudan

Abstract

Introduction: Gadarif is an endemic area of medical disorders causing splenomegaly in patients who are also subjected to abdominal trauma. Despite the lack of resources, which make adherence to the international guidelines of NOMSI somehow difficult, we apply it based on clinical evaluation, laboratory tests and ultrasound.

Objectives: To study the outcome of NOMSI based on hemodynamic stability, ultrasound findings and follow-up.

Methods: A prospective analytic hospital based study conducted in Gadarif, Eastern Sudan from 2015 to 2019, including patients who were having splenic injury with no clear indication for immediate surgery.

Results: A total of 30 patients were included, of them 29 (96.7\%) were male. Their age ranges between 7-65 years with the mean of 29.8. Twenty patients (66.7\%) presented within 24 hours from trauma, while the rest presented later. Three patients (10\%) had no history of abdominal trauma, one is an epileptic and the other 2 had concomitant severe malaria. Hemodynamic instability at presentation was found in 14 patients $(46.7 \%)$. Left hypochondrial pain was the predominant symptom in 20 patients $(66.7 \%)$ and two thirds of patients had tender LHQ. More than half (53.3\%) had splenic hematoma/laceration on initial ultrasound. We encountered 5 (16.6\%) patients with pathological spleens of Malaria or Visceral Leishmaniasis (Kala-azar). Four patients (13.3\%), of those who had increased spleen size on initial US scan, were hemodynamically unstable and required emergency splenectomy resulting in a success rate of NOMSI in $86.7 \%$.

Conclusion: NOMSI based on clinical judgment and ultrasound examination in limited resources setup, is feasible and applicable with comparable success rates. Further studies are needed to evaluate NOMSI in endemic areas with pathological spleen.

Keywords: Splenic injuries; Spleen; Liver; Healthy immune function; Ultrasound examination; Focused abdominal sonography

Abbreviations: NOMSI: Non-Operative Management of the Splenic Injuries; SNOM: Selective Non-Operative Management; CT: Computerized Tomography; FAST: Focused Abdominal Sonography of Trauma

\section{Introduction}

Splenic injuries whether from penetrating or blunt trauma to the abdomen are common and can be lethal. Spleen, along with the liver are the most commonly injured solid abdominal organ [1] and it is incidence may reach up to $45.6 \%$ in some studies [2]. Formerly splenectomy was the treatment of all splenic injuries, however, nowadays it has been replaced by NOMSI as the most common conservative method [3], thus preserving the spleen has a vital role in healthy immune function [4], yet splenectomy may still be required in some situations [1].
In this case series we studied the feasibility of non-operative management in a limited resources hospital utilizing serial clinical assessment, laboratories investigations and abdominal ultra-sounds with a success rate of $86.7 \%$.

\section{Patients and Methods}

This is a hospital based, prospective, observational analytic study conducted in Gadarif Teaching Hospital, Eastern Sudan, in 
the Period between 2015 and 2019. All patients who presented with blunt trauma and confirmed splenic injury, whether healthy or diseased, were included governed with their hemodynamic instability (i.e.: one or more out-of-range vital sign measurements or clinical features of circulatory shock) [5,6]. Patients who presented in hypovolemic shock which failed to respond to resuscitation or penetrating abdominal trauma were taken directly to laparotomy was excluded. After explanation and signing an informed consent the data was collected by a senior surgical registrar using pretested questionnaire, which include sociodemographic characteristics, history of trauma, time to hospital arrival and history of febrile illnesses. Vital signs, abdominal examination and baseline investigations including FAST (Focused Abdominal Sonography of Trauma) scan were done.

Thirty patients were included in the study, for each patient we assured monitoring of vital signs, strict bed rest, frequent monitoring of blood counts, serial abdominal examinations alert theatre team with blood bank service available and a surgical registrar is nominated throughout the first 48 hours in the high dependency unit or general ward. Ultrasound done initially and at 2 weeks interval for all patients.

\section{Results}

This study includes 30 patients, their age ranges from 7 - 65 years with a mean age of 29.8 years $(S D \pm 14.4$ ). Eighteen patients (50\%) fall in the age groups of 21 - 30 years. There was only 1 female patient making a male to female ratio of 29:1.In this series, 20 patients $(66.7 \%)$ presented within the first 24 hours, three patients $(10 \%)$ presented within 24 to 72 hours while 7 patients $(23.3 \%)$ presented more than 72 hours after injury. Blunt abdominal trauma was the predominant mechanism of injury occurring in 27 patients (86.7\%) 4 of them was found to have pathological spleen 3 patients (10\%) with severe malaria and 1 patient who is diagnosed as Kala-azar. Three patients (10\%) patients had no remarkable history of trauma, 1 was an epileptic patient and 2 were proven cases of severe malaria suggested to have spontaneous rupture of spleen. Making a total of 6 patients (20\%) having a pathological spleen. Left hypochondrial pain was the predominant presenting symptom in 23 cases $(76.7 \%)$ On Clinical abdominal examination 3 cases (10\%) had a soft lax abdomen, while tenderness was detected in LHQ in 20 (66.7\%), generalized in 6 (20\%), and hypogastric in 1 (3.3\%) patient (Table 1).

Table 1: Demographic data and clinical presentation $(\mathrm{N}=30)$.

\begin{tabular}{|c|c|c|c|c|}
\hline \multicolumn{3}{|c|}{ Variable } & No $=30$ & $\%$ \\
\hline \multirow{3}{*}{ Age } & Mean & & \multicolumn{2}{|c|}{29.8 years } \\
\hline & Range & & \multicolumn{2}{|c|}{$7-65$ years } \\
\hline & SD & & \multicolumn{2}{|c|}{14.393} \\
\hline \multirow{2}{*}{ Sex } & Male & & 29 & $96.70 \%$ \\
\hline & Female & & 1 & $3.3 \%$ \\
\hline \multirow{2}{*}{ Marital Status } & Married & & 13 & $43.30 \%$ \\
\hline & Single & & 17 & $46.70 \%$ \\
\hline \multirow{3}{*}{ Time to presentation } & $<24$ hours & & 20 & $66.70 \%$ \\
\hline & $24-72$ hours & & 3 & $10 \%$ \\
\hline & $>72$ hours & & 7 & $23.30 \%$ \\
\hline \multirow{3}{*}{ History of Trauma } & Yes & & 27 & $90 \%$ \\
\hline & \multirow{2}{*}{ No } & Malaria & 2 & $6.70 \%$ \\
\hline & & Epilepsy & 1 & $3.30 \%$ \\
\hline \multirow{3}{*}{ Hemodynamic Stability } & Stable & & 16 & $53.30 \%$ \\
\hline & \multirow{2}{*}{ Unstable } & IV Fluid Resuscitation & 5 & 16.3 \\
\hline & & Blood Transfusion $(\mathrm{Hb}<50 \%)$ & 9 & $30 \%$ \\
\hline \multirow{4}{*}{ Abdominal Tenderness } & Lt Hypochondrial & & 20 & $66.70 \%$ \\
\hline & Generalized & & 6 & $20 \%$ \\
\hline & Hypogastric & & 1 & $3.30 \%$ \\
\hline & Non & & 3 & $10 \%$ \\
\hline
\end{tabular}

Sixteen patients (53.3\%) were hemodynamically stable at time of presentation and the others responded to initial resuscitation with IV fluids. Blood was transfused to only those who had hemoglobin below $7 \mathrm{gm} / \mathrm{dl}$ on admission or remains hypotensive after the initial fluid resuscitation $[7,8]$. Nine patients $(30 \%)$ received blood transfusions throughout their hospital stay. FAST scan was done initially in this study to all patients on admission in order to confirm the diagnosis and evaluate the size of spleen, 
presence of free fluid and splenic injury as reported in form of hematoma and/or laceration. Another follow-up ultrasound examination is done two weeks later in $26(86.7 \%)$ patients, as 4 patients underwent splenectomy. The follow-up ultrasound examination demonstrated that the spleen size returns to normal all patients except 3 (11.5\%) while the sub-capsular hematoma/ laceration which was detected in 14 patient (46.7\%) is either resolved completely or had decreased considerably in 10 patients (33.3\%). The 4 patients who underwent splenectomy was due to expanding hematoma in 3 and one patient was found to have a splenic abscess (Table 2).

Table 2: Serial US findings, Initial and 2 weeks later:

\begin{tabular}{|c|c|c|c|c|c|c|c|}
\hline \multicolumn{4}{|c|}{ Initial US } & \multicolumn{4}{|c|}{2 Weeks Follow-up US } \\
\hline & & No & $\%$ & & & No & $\%$ \\
\hline \multirow{3}{*}{ Spleen size } & Increased & 14 & $46.70 \%$ & Increased & & 3 & $10 \%$ \\
\hline & Normal & 16 & $53.30 \%$ & Normal & & 23 & $76.70 \%$ \\
\hline & & & & Splenectomy & & 4 & $13.30 \%$ \\
\hline \multirow{4}{*}{$\begin{array}{c}\text { Sub-capsular Hematoma/ } \\
\text { laceration }\end{array}$} & No & 16 & $53.30 \%$ & & & 16 & $53.30 \%$ \\
\hline & & & & Normal & & 10 & $33.30 \%$ \\
\hline & Yes & 14 & $46.70 \%$ & Splenectomy & $\begin{array}{l}\text { Increased } \\
\text { size }\end{array}$ & 3 & $10 \%$ \\
\hline & & & & & Abscess & 1 & $3.30 \%$ \\
\hline \multirow{3}{*}{ Free fluid } & No & 17 & $56.70 \%$ & No & & 26 & $86.70 \%$ \\
\hline & & & & yes & & 0 & $0.00 \%$ \\
\hline & yes & 13 & $33.30 \%$ & Splenectomy & & 4 & $13.30 \%$ \\
\hline
\end{tabular}

\section{Discussion}

Historically, in 1882 Gross indicated NOM for spleen injuries and Billroth suggested over 100 years ago that the injured spleen has the ability of self-healing [9]. In 1903 Senn described Non Operative Management of the Splenic Injuries [5]. NOMSI is currently used in up to $70 \%$ of patients with documented blunt trauma to spleen [3]. Decision to employ NOM pathway for blunt splenic injury requires the patient to meet several criteria, the 1st and foremost is hemodynamic stability and absence of any suspected associated intra-abdominal injury [4].

To explore the efficacy of NOM of splenic and hepatic injury the literature search identified 73 articles specifically addressing it, of which 66 concluded that NOMSI was appropriate for selected hemodynamically stable patient being the most reliable criterion.

Thirty percent of the patients in this study required blood transfusion. It is agreed upon that non operative management does not carry a greater need for transfusion than operative management [9-11]. Many studies suggested that blood requirement with NOMSI is actually less than with operative management for injuries of similar grades [12,13]. Isameldin and Aamir In their study which was conducted in Khartoum the capital of Sudan 3 main hospitals, adopting Selective NonOperative Management (SNOM)(7, found that blood transfusion was required in $42 \%$ of their patients. This could be attributed to the fact that they were adopting SNOM and included cases of penetrating abdominal trauma in their series. Although penetrating abdominal trauma was excluded from our patients, actually it wasn't encountered much in our area. This discrepancy might be attributed to variations in cultural context of the different communities and mechanism of injury between rural and urban areas.

Computerized Tomography (CT) scan is the most accurate, specific, and sensitive in delineating the extent and severity of injury [14-17], thus it is often recommended, but it is clear from multiple studies that neither the grade of injury nor the degree of haemoperitoneum on CT scan can predict the outcome of NOMSI, while hemodynamic status of the patient remains the most reliable criteria for nonoperative management [18-22]. Isameldin and Aamir in their study, which was conducted in 3 main hospitals of Khartoum, did CT scan in half of their 66 patients, while none of our patients had a CT scan. Despite this, hemodynamic stability remains the foremost criterion for the successful NOMSI in both studies [8].

We encountered 6 patients with injured pathological spleen, interestingly 2 of them had no history trauma but have documented severe malaria, which suggests spontaneous rupture of spleen and the third one is a known epileptic patient on treatment but he could not recall a history of trauma. Three more patients of malaria and 1 with visceral leishmaniasis (Kala-azar) had a positive history of trauma. All these 6 patients responded effectively to NOMSI. Agbakwuru et al from Nigeria reported a success rate of $25 \%$ in patients who had NOMSI and $70 \%$ were managed with splenorrhaphy and $5 \%$ had partial splenectomy in 
their study of 20 patients who had tropical malarial splenomegaly undergone splenic preservation [23]. Mohamed Osman et al from USA reported successful NOMSI of malarial splenic rupture in 2 cases in Khartoum. The international literature reported a success rate of $71 \%$ [24]. In this study we have successful NOMSI in all (100\%) pathological spleen

Literature is very scares regarding NOMSI in patients with visceral leishmaniasis (Kala-azar). In 2017 WHO update, Visceral Leishmaniasis is reported as highly endemic in Indian subcontinent and east Africa with an important foci in Gadarif State where we did our study and where the disease is a real economic burden [25-28]. Nevertheless we used to see spontaneous rupture of spleen in malarial tropical splenomegaly rather than patients with Kala-azar.

\section{Conclusion}

Non Operative Management of Splenic Injuries (NOMSI) based on clinical judgment and ultrasound in a limited resources setup, is feasible and applicable with comparable success rates. Large number studies are needed to evaluate NOMSI in areas endemic with pathological spleens.

\section{References}

1. The America Association for the Surgery of Trauma. Blunt Splenic Trauma

2. Gianluca Costa, Simone Maria Tierno, Federico Tomassini, Luigi Venturini, Barbara Frezza, et al. (2010) The epidemiology and clinical evaluation of abdominal trauma. An analysis of a multidisciplinary Trauma Registry. Ann Int Chir 81(2): 95-102.

3. George C, L S Chan, E Kamel, J A Murray, N Yassa, D Kahaku, et al. (2000) Nonoperative management of Splenic Injury. Have We Gone Too Far? Arch Surg 135(6): 674-681.

4. Bradburn, DO Heidi, L Frankel (2010) Diagnosis and Management of splenic Trauma. The Journal of Lancaster General Hospital 5: 125-129.

5. Weil MH (2005) Defining Hemodynamic Instability. Chapter in Functional Hemodynamic Monitoring. Update in Intensive Care and Emergency Medicine 42: 9-17.

6. Eastern Association for the Surgery of Trauma (EAST) Ad Hoc Committee on Practice Management Guideline Development. Nonoperative management of blunt injury to the liver and spleen 2003.

7. Beuran M, Gheju I, Venter, Marian RC, Smarandache R (2012) Nonoperative management of splenic trauma. J Med Life 5(1): 47-58.

8. Isameldin O Ibrahim, Aamir A Hamza, M E Ahmed (2013) Traumatic Splenic Injuries in Khartoum, Sudan. Surgical Science 4: 525-552.

9. Lucas CE (1991) Splenic Trauma-Choice of Management. Ann. Surg 213(2): 98-112.

10. Jeffrey RB, Laing FC, Federle MP, Goodman PC (1981) Computed tomography of splenic trauma. Radiology 141(3): 729-732.

11. Federle MP, Crass RA, Jeffrey RB, Trunkey DD (1982) Computed tomography in blunt abdominal trauma. Arch Surg 117(5): 645-650.
12. Kaufman RA, Towbin R, Babcock DS, Gelfand MJ, Guice KS, et al. (1984) Upper abdominal trauma in children: Imaging evaluation. AJR Am J Roentgenol 142(3): 449-460.

13. Morse MA, Garcia VF (1994) Selective nonoperative management of pediatric blunt splenic trauma: Risk for missed associated injuries. J Pediatr Surg 29: 23-27.

14. Schwartz MZ, Kangah R (1994) Splenic injury in children after blunt trauma: Blood transfusion requirements and length of hospitalization for laparotomy versus observation. J Pediatr Surg 29(5): 596-598.

15. Taylor GA, Fallat ME, Potter BM, Eichelberger MR (1988) The role of computed tomography in blunt abdominal trauma in children. J Trauma 28(12): 1660-1664.

16. Croce MA, Fabian TC, Menke PG, Waddle-Smith L, Minard G, et al. (1995) Nonoperative management of blunt hepatic trauma is the treatment of choice for hemodynamically stable patients. Results of a prospective trial. Ann Surg 221(6): 744-755.

17. Rutledge R, Hunt JP, Lentz CW, Fakhry SM, Meyer AA, et al. (1995) A statewide, population based time-series analysis of the increasing frequency of nonoperative management of abdominal solid organ injury. Ann Surg 222(3): 311-326.

18. Becker CD, Spring P, Glattli A, Schweizer W (1994) Blunt splenic trauma in adults: Can CT findings be used to determine the need for surgery? AJR Am J Roentgenol 162(2): 343-347.

19. Sutyak JP, Chiu WC, D’Amelio LF, Amorosa JK, Hammond JS (1995) Computed tomography is inaccurate in estimating the severity of adult splenic injury. J Trauma 39(3): 514-518.

20. Sherman HF, Savage BA, Jones LM, Barrette RR, Latenser BA, et al. (1994) Nonoperative management of blunt hepatic injuries: Safe at any grade? J Trauma 37(4): 616-621.

21. Ruess L, Sivit CJ, Eichelberger MR, Taylor GA, Bond SJ (1995) Blunt hepatic and splenic trauma in children: Correlation of a CT injury severity scale with clinical outcome. Pediatr Radiol 25(5): 321-325.

22. Goldstein AS, Sclafani SJ, Kupferstein NH, Bass I, Lewis T, et al. (1985) The diagnostic superiority of computerized tomography. J Trauma 25(10): 938-946.

23. Allins A, Ho T, Nguyen TH, Cohen M, Waxman K, et al. (1996) Limited value of routine follow up CT scans in nonoperative management of blunt liver and splenic injuries. Am Surg 62(1): 883-886.

24. E.A Agbakwuru, A.A Akinkuolie, O.A Sowande (2008) Splenic Injuries in a Semi Urban Hospital in Nigeria. East and Central African Journal of Surger 13: 95-100.

25. Mohamed F Osman, Isam M Elkhidir, Selwyn O Rogers Jr, Mallory Williams (2012) Non-operative management of malarial splenic rupture: The Khartoum experience and an international review. International Journal of Surgery 10(9): 410-414.

26. Yolanda Kathrin Mueller, Fabienne Nackers, Khalid A Ahmed, Marleen Boelaert, Jean-Claude Djoumessi, et al. (2012) Burden of Visceral Leishmaniasis in Villages of Eastern Gadarif State, Sudan: An Exhaustive Cross-Sectional Survey. PLOS Negl Trop Dis 11: 1-6.

27. Leishmaniasis (2017) WHO. Factsheet.

28. F Meheus, Abuzaid A Abuzaid, Rob Baltussen, Brima M Younis, Manica Balasegaram, et al. (2013) The Economic Burden of Visceral Leishmaniasis in Sudan: An Assessment of Provider and Household Costs. Am J Trop Med Hyg 89(6): 1146-1153. 
